\title{
Os novos modelos de negócio da música digital e a economia da atenção
}

The New Digital Music Business Models and the Attention Economy Les nouveaux modèles d'affaire de la musique digitale et l'économie de l'attention

Leonardo Ribeiro da Cruz

\section{(2) OpenEdition}

\section{Journals}

\section{Edição electrónica}

URL: http://journals.openedition.org/rccs/6296

DOI: $10.4000 /$ rccs.6296

ISSN: 2182-7435

\section{Editora}

Centro de Estudos Sociais da Universidade de Coimbra

Edição impressa

Data de publição: 1 maio 2016

Paginação: 203-228

ISSN: 0254-1106

\section{Refêrencia eletrónica}

Leonardo Ribeiro da Cruz, « Os novos modelos de negócio da música digital e a economia da atenção

», Revista Crítica de Ciências Sociais [Online], 109 | 2016, posto online no dia 18 maio 2016, consultado o 14 novembro 2019. URL : http://journals.openedition.org/rccs/6296 ; DOI : 10.4000/rccs.6296 


\section{LEONARDO RIBEIRO DA CRUZ}

\section{Os novos modelos de negócio da música digital e a economia da atenção}

O presente artigo busca analisar as estratégias de inserção do mercado fonográfico no ambiente digital, em especial os novos serviços gratuitos de streaming por demanda. Aborda-se a mudança da natureza comercial da música - que deixa de ser comercializada diretamente para ser valorizada como um serviço do marketing comportamental e como esse novo modelo tem, como pressuposto, por um lado, as características de abundância e gratuidade da música e, por outro, a valorização dos dados de navegação e do tempo de atenção dos usuários. Por fim, o texto discute o modo como esse novo serviço fomenta a hegemonia da economia da atenção on-line e da vigilância ubíqua e auxilia na expansão de ambientes digitais fechados, produzidos unicamente pelo mercado em detrimento de espaços livres e abertos.

Palavras-chave: economia da atenção; estratégias de marketing; indústria fonográfica; música digital; streaming de áudio.

\section{Introdução}

Desde o ano de 2008, tem-se apontado a música digital como uma promessa para salvar um mercado de música gravada em crise. ${ }^{1}$ Hoje, os diversos modelos de negócio da música digital - em especial a venda direta de música e o acesso em diversos tipos de sites de streaming ${ }^{2}$ - possuem uma importância crucial nos desdobramentos do mercado. Além de ganhos

\footnotetext{
${ }^{1}$ Em 2007, o mercado digital de música gravada alcançou 15\% de todo o rendimento do mercado fonográfico (IFPI, 2008: 05) e apresentou um crescimento de 40\% em um ano (ibidem: 06). Já 2011 foi um ano emblemático para o setor da música digital quando, nos Estados Unidos da América, o rendimento do mercado digital de música alcançou $50 \%$ de todo o rendimento do mercado fonográfico e, pela primeira vez desde 2004, o rendimento do mercado fonográfico estadunidense apresentou crescimento (RIAA, 2012).

${ }_{2} \mathrm{O}$ serviço de streaming se caracteriza por ser um espaço onde o usuário consegue acessar certos tipos de produtos culturais (como música ou vídeos) sem precisar realizar um download do arquivo executado. Neste sentido, o produto só será executado se o usuário estiver conectado à internet e ao serviço executante.
} 
em receita, os meios digitais de distribuição legal de música são responsáveis por apresentar novas opções de promoção, popularização e logística de distribuição da música gravada. Essas opções, em diversos casos, apresentam novos tipos de relação entre o mercado fonográfico e o público consumidor e entre os atores do mercado musical e apresentam ainda modos inovadores de fruição musical, de forma legal e diversificada.

Esse artigo - que apresenta uma parte dos resultados de uma pesquisa de doutorado intitulada "Internet e arquiteturas de controle: as estratégias de repressão e inserção do mercado fonográfico digital” (Cruz, 2014) tem como objetivo discutir alguns dos desdobramentos apresentados pelos novos modelos de negócio da música digital: a popularização dos serviços de streaming e a oferta abundante de música; o crescimento do modelo de acesso à música, das estratégias de financiamento por publicidade e a diversificação do cariz comercial da música; a hegemonização dos espaços financiados pelas estratégias da publicidade comportamental e o papel do público consumidor na valorização desses espaços e, finalmente, as novas diretrizes da chamada "economia da atenção" (Goldhaber, 1992, 1997; Lanham, 1994) e o aprofundamento do paradigma da sociedade de controle (Deleuze, 1994).

Qual é o papel do público consumidor nesse modelo? Por ser tão amplo e complexo, não foi possível esgotar este tema nem abordar alguns desdobramentos importantes nesse espaço. Por este motivo optou-se por abordar o tema a partir do recorte do mercado, embora de uma forma crítica. Questões relacionadas às transformações estéticas apresentadas pelos novos suportes de música, bem como uma análise dos novos modelos de fruição da música sob o ponto de vista do público consumidor ou dos artistas também tiveram que ser deixadas de lado. Por fim, os desdobramentos tecnopolíticos das decisões tomadas por esse mercado - como a ampliação da vigilância ubíqua; a transformação da vigilância econômica em vigilância política; ou a influência da economia da atenção na transformação da topologia da internet - não encontraram aqui, também, espaço para ser desenvolvidos, devendo ser tema para um outro artigo.

$\mathrm{Na}$ realização dessa empreitada, essa investigação se utiliza de pesquisas empíricas sobre o mercado fonográfico atual, bem como de pesquisas exploratórias sobre os novos ambientes de acesso à música digital. Foram utilizados dados secundários retirados, em grande parte, dos relatórios anuais da Federação Internacional da Indústria Fonográfica (IFPI - International Federation of the Phonographic Industry), intitulados IFPI Digital Music Report (IFPI, 2015). Tais dados referem-se ao mercado mundial de música gravada e são obtidos através dos relatórios de marketing das 
diversas associações nacionais federadas - como a Associação Brasileira dos Produtores de Disco (ABPD), a Associação Americana das Indústrias de Gravação (RIAA - Recording Industry Association of America) ou a Associação Fonográfica Portuguesa - e das indústrias fonográficas associadas. A IFPI possui cerca de 1300 membros em 61 países. Foram utilizados ainda dados globais e locais relacionados ao crescimento dos serviços de streaming (Nielsen, 2014, 2015; RIAA, 2012) e à diminuição da contrafação de música digital (NPD, 2012; IPSOS, 2013; Aguiar, 2015). Não tendo sido encontrados os dados globais, utilizaram-se os dados locais, que serviram para ilustrar algumas tendências importantes, mesmo que em espaços geograficamente restritos.

Já os dados relacionados ao funcionamento dos serviços de streaming, seus termos de uso e de privacidade foram obtidos através de pesquisas exploratórias realizadas nos sites e aplicativos dos serviços disponíveis no Brasil, lugar onde essa pesquisa foi realizada. Embora os termos de uso sejam semelhantes em todos os países onde o serviço é executado - e bastante semelhantes até entre as diversas empresas de streaming -, eles devem se adequar às leis locais de proteção de dados, privacidade, etc.

Da mesma forma, fizemos uso de referenciais diversos para conceitualizar a nova economia do acesso (Rifkin, 2001; Santos, 2003), a economia da atenção (Goldhaber, 1997; Crary, 2013; Freire, 2012; Senra, 2013) e as sociedades de controle (Deleuze, 1994; Foucault, 2004; Virilio, 1999).

Como resultado, é intenção do presente artigo apresentar as características de um novo mercado global de música gravada assente nas formas de valorização da publicidade comportamental. A eficiência desse mercado diz respeito à possibilidade, aberta pelo marketing, de mobilizar estratégias comerciais que consigam valorizar um ambiente voltado à abundância e à gratuidade. Em contrapartida, tais estratégias inserem o mercado fonográfico em um novo mercado de dados, em que, ao oferecer um ambiente seguro e abundante de acesso à música e apresentar uma nova e eficiente forma de fruição de música, conseguem se valorizar através dos dados de navegação de seus usuários e seu tempo de atenção.

Esse modelo não é novo e não foi inaugurado pelo mercado fonográfico. Ele está se tornando hegemônico na rede e, por se basear em espaços fechados cuja valorização se dá pelo acesso e pela permanência do usuário, está alterando definitivamente a topologia da internet. A adesão do mercado da música nesse novo filão do capitalismo digital só faz expandir ainda mais esses espaços e, por consequência, ampliar o escopo da vigilância ubíqua montada pelo marketing. 


\section{Streaming de música e o problema da abundância}

Ao analisar a história do mercado de música gravada, podemos observar o protagonismo das tecnologias de gravação, de cópia e de suporte técnico em seu desenvolvimento. O fonógrafo e o gramofone, as gravações elétricas, a fita magnética, a gravação multicanal, a evolução das tecnologias de estúdio e de fábrica alteraram definitivamente a trajetória do mercado da música e a relação entre seus atores.

As tecnologias digitais de distribuição foram as últimas tecnologias a influenciar os rumos dos atores desse mercado. Enquanto o grande mercado fonográfico ainda buscava se valorizar através da venda de mídia física, os usuários da internet, empoderados pelo grande barateamento da produção e distribuição de cópias digitais dos produtos culturais - propiciado pelo uso do computador e das redes digitais como meios de produção -, se empenharam em construir ambientes eficientes e não autorizados de distribuição gratuita de música digital, provocando um enorme ruído nos canais de distribuição e de promoção das grandes indústrias.

Nesse cenário, as primeiras manifestações das empresas fonográficas na internet foram as de repressão através da expansão e endurecimento das leis autorais. A oferta gratuita de músicas digitalizadas em um ambiente propício à distribuição abundante, eficiente e com a possibilidade de oferta de uma quantidade maior de música fez com que as maiores empresas do setor se sentissem ameaçadas. ${ }^{3}$

Contudo, a grande demanda por abundância de títulos - somada à crescente popularização de aparelhos reprodutores de música digital - apontou para um caminho bastante lucrativo para as empresas fonográficas, que marcou a primeira estratégia de inserção do grande mercado musical na internet: a venda direta de música digital. De maneira geral, esse serviço funciona através de empresas especializadas que fazem acordos com as gravadoras para disponibilizarem suas músicas para a venda, pagando-lhes parte do lucro direto sob a forma de royalties de direitos autorais. Tais empresas são novos atores dentro do mercado fonográfico. Conhecidas como "serviços de música digital”, elas negoceiam os royalties com as gravadoras e selos, digitalizam os acervos, criam os ambientes on-line para negociar diretamente as músicas com os consumidores on-line, etc. Tais empresas, portanto, não surgiram dentro do tradicional mercado musical e não pertencem ao portfólio das grandes gravadoras.

\footnotetext{
3 Para uma análise mais completa em relação às estratégias de repressão do mercado fonográfico sobre o compartilhamento de arquivos, ver o artigo "RIAA vs. The People: Four Years Later", da fundação Electronic Frontier Foundation. Consultado a 08.04.2016, em http://w2.eff.org/IP/ P2P/riaa_at_four.pdf.
} 
Contudo, a venda direta de música digital, embora manifeste enormes vantagens ao desvincular a música de seu suporte de distribuição, não apresenta uma grande inovação no modelo já consolidado do mercado musical. O paradigma continua a ser a venda de produtos no mercado da música gravada e a transferência de posse. Esta só pode fazer concorrência à distribuição gratuita e não autorizada de música a partir do discurso da legalidade e da segurança, mas não apresenta vantagem em relação à gratuidade ou à abundância. A venda de música on-line continua a colocar a aquisição de bens culturais no regime de escassez. A propriedade ainda é o paradigma e seu modelo depende do controle sobre a sua troca entre vendedores e compradores no mercado. A internet é, para esse modelo, um novo tipo de suporte e de forma de distribuição, muito embora a comercialização de música na forma de download continue constituindo a maior parcela de rendimentos para a distribuição de música digital, somando 52\% dos ganhos globais desse setor em 2014 (IFPI, 2015).

Contudo, o mercado fonográfico - e todo o mercado de bens culturais começa a esboçar novos modelos de negócio que marcam uma alternativa ao paradigma da troca de propriedade. Novos serviços de streaming por demanda se apoderam da tendência para a abundância e a gratuidade da transmissão de dados da internet para redefinir o papel da música, do mercado e do consumidor - aqui mais propriamente um usuário. Oferecer bens em abundância e gratuitamente aos usuários foi a última e derradeira lição aprendida pelo mercado fonográfico com o compartilhamento de arquivos. Hoje, como bem define Cory Doctorow (2012), a abundância se tornou a característica essencial de toda a mídia, e é peça-chave para o novo modelo de negócios baseado no acesso.

Até agora existem dois modelos predominantes de serviços de streaming. Os que se configuram como uma rádio on-line, que permitem que os usuários acessem passivamente uma seleção de música, e os serviços interativos por demanda, que permitem que os usuários escolham as músicas que gostariam de ouvir. Diferente dos serviços de download de músicas, nos serviços de streaming, a música não fica, a princípio, disponível no computador do usuário. ${ }^{4}$ Este somente tem acesso à música quando está on-line e dentro do ambiente virtual da empresa que disponibiliza o serviço.

As músicas são ofertadas, em alguns modelos, gratuitamente e em grande quantidade e a receita é gerada por publicidade e/ou pela venda de

\footnotetext{
${ }^{4}$ Tecnicamente, quando um usuário acessa a música em um servidor, partes pequenas da música são temporariamente copiadas para seu computador, permanecendo lá somente pelo tempo de sua reprodução.
} 
contas premium, em que o usuário paga uma quantia mensal para fazer o download da música, ouvi-la com melhor qualidade técnica e sem ser interrompido por anúncios publicitários. Há vários serviços desse tipo, sendo estes os que revelam maior crescimento na rede. Em 2013, em dados publicados pela empresa de pesquisa Nielsen, com contribuição da Billboard, ao menos no mercado estadunidense, o rendimento das vendas de música digital caiu 6\%, enquanto a renda gerada através dos serviços de streaming de música subiram 32\% (Nielsen, 2014). Já em 2014, segundo o relatório da IFPI, os rendimentos dos serviços de streaming de música tiveram crescimento de $39 \%$ e representavam $23 \%$ do mercado de música digital global, enquanto a venda direta de música teve uma queda de 8,1\% (IFPI, 2015). No mercado estadunidense, segundo relatório da Nielsen Music, o número de músicas acessadas por streaming aumentou 53\% em 2014 (chegando ao total de 164 bilhões de acessos), enquanto o número de músicas vendidas caiu 12,5\% (aproximadamente 1,3 milhões) (Nielsen, 2015). Já no Brasil, país onde essa pesquisa foi realizada, o streaming cresceu $22 \% \mathrm{em}$ 2014 e passou a representar 51\% do faturamento de música digital. O país foi um dos destaques no IFPI Digital Music Report 2015. O relatório celebra as parcerias realizadas entre as empresas de streaming e as de telecomunicações, como a TIMmusic by Deezer ou a Vivo Música by Napster.

Os serviços de streaming por demanda, como o de venda direta de música digital, são prestados por empresas parcialmente independentes das grandes gravadoras. Elas procuram gerar receita e, por meio dela, ou pagam o licenciamento das músicas ou oferecem um acordo de percentagem de lucros de publicidade. ${ }^{5}$ Como em todos os serviços baseados em publicidade, há várias especulações sobre a sua sustentabilidade. ${ }^{6}$ A maior questão é que, segundo tais análises, os ganhos com publicidade não são suficientes para pagar o direito autoral das músicas distribuídas.

Contudo, atualmente podemos perceber um aumento do interesse de participação real no mercado de música digital por parte das grandes empresas de música gravada. Elas se aproveitam do seu papel peculiar na cadeia econômica desse novo modelo de negócio - sem a autorização para que os fonogramas sejam utilizados pelos serviços digitais, estes se tornam ilegais ou têm uma oferta muito reduzida de música - para angariar uma participação nas start-ups de entretenimento digital, em especial as de streaming de música. Segundo Zack O’Milley Greenburg, no artigo “Como as gravadoras estão se

\footnotetext{
${ }^{5}$ Cf. http://www.numerama.com/magazine/10016-Deezer-rapporte-uniquement-70000-euros--la-Sacem-en-six-mois.html, consultado a 08.04.2016.

${ }^{6}$ Cf. http://www.guardian.co.uk/technology/blog/2009/oct/08/spotify-internet; http://remixtures. com/2009/01/deezer-em-busca-da-sobrevivencia/. Consultados a 08.04.2016.
} 
apoderando da multibilionária revolução digital” (2015), em outubro de 2014 a Warner Music Group se tornou a primeira grande gravadora a fechar uma parceria com uma start-up do género, tendo adquirido $5 \%$ da empresa por um valor superior a 120 milhões de dólares americanos. Segundo o artigo, esse valor foi negociado com um desconto de $50 \%$ nas ações da empresa.

O caso da Warner foi o primeiro de muitos. Segundo o citado artigo, todas as três grandes empresas do concentrado mercado fonográfico atual - nominalmente a Warner Music Group, a Universal Music e a Sony Music obtêm participação nos negócios das start-ups de música ou de entretenimento em geral, e na sua maioria em condições muito vantajosas. Algumas vezes, inclusivamente, de forma gratuita. Em troca, as gravadoras concedem a autorização de reprodução de seus valiosos fonogramas (Greenburg, 2015).

Atualmente, os maiores serviços internacionais de streaming de música chegaram ao Brasil. Entre eles estão o Deezer, ${ }^{7}$ Spotify, ${ }^{8}$ Apple Music, ${ }^{9}$ Tidal ${ }^{10}$ e Napster. ${ }^{11}$ No Brasil, os três primeiros oferecem serviços gratuitos

\footnotetext{
7 O Deezer é um serviço de streaming por demanda criado na França em 2007. É considerado o primeiro serviço de streaming que conseguiu se legalizar. Chegou ao Brasil em 2013 e possui parceria com os sites e serviços de telefonia no país. É o serviço de streaming mais utilizado na Europa. Presente em 182 países, o serviço possui contratos de licenciamento com as três grandes gravadoras e com mais de 100 selos em todo o mundo. Assim, oferece mais de 35 mil músicas em seu acervo para mais de 6 milhões de usuários pagantes (Deezer.com)

${ }^{8}$ O Spotify é um serviço sueco de streaming de música por demanda, criado em 2008 pela empresa Spotify AB. Possui cerca de 75 milhões de usuários - sendo 20 milhões usuários assinantes - em 64 países. Oferece serviços gratuitos - com baixa qualidade de áudio e com peças publicitárias entre as faixas de música - e serviços pagos, com melhor qualidade de áudio e sem publicidade.

9 A Apple Music é um recente serviço de streaming da empresa Apple Inc. Lançado em 100 países, inclusive no Brasil, em 30 de junho de 2015, o serviço já conta com 37 milhões de músicas em seu acervo e já possui mais de 15 milhões de usuários. A Apple foi uma das grandes responsáveis pela popularização da venda de música digital com seu serviço iTunes. Com o crescimento dos serviços de streaming, busca agora fazer concorrência com as grandes empresas do setor, como o Spotify e o Deezer.

${ }^{10} \mathrm{O}$ serviço de distribuição digital de música Tidal foi uma iniciativa de grandes artistas para combater as baixas remunerações repassadas pelos grandes serviços de streaming. Lançado em março pelo artista Jay Z, o serviço conta com o apoio de Beyoncé, Madonna, Kanye West, Rihanna, Taylor Swift, Nicki Minaj, Alicia Keys, entre outros. O serviço, além de oferecer música em alta qualidade, pretende impor um novo modelo de remuneração para os artistas, repassando $75 \%$ dos ganhos diretamente aos escritores, cantores e músicos executantes. Os artistas engajados nesse novo modelo acusam os grandes serviços de streaming de remunerar muito pouco os setores criativos e ceder parte de seus dividendos às grandes gravadoras.

${ }^{11}$ O Napster foi criado como um serviço ilegal de compartilhamento de arquivos por Shawn Fanning e Sean Parker em 1999 e foi um dos maiores protagonistas da transformação do mercado da música. A partir do uso massivo de suas redes, o programa apresentou uma forma rápida, gratuita e abundante de aquisição de música e alterou, definitivamente, a forma de fruição musical no começo do século xxı. Em 2001, o serviço foi fechado após um longo e noticioso processo jurídico movido por titulares de direitos autorais. A marca e o logotipo do Napster foram então vendidos à empresa Roxio em 2003 e, em 2008, foram adquiridos pela empresa Best Buy. Atualmente, o Napster se uniu ao serviço de streaming Rhapsody e se tornou a marca da empresa nos países da América Latina e na Europa. Atualmente conta com 2,5 milhões de assinantes.
} 
de streaming financiados por publicidade no site e/ou entre as músicas, com algumas limitações. O serviço Deezer limita a utilização de seu aplicativo para smartphone e não permite que suas músicas sejam acessadas de forma offline. O Spotify oferece um serviço gratuito com limitações na quantidade de músicas ofertadas, na qualidade do áudio, com a possibilidade de ouvir músicas offline e limitando o número de vezes que o usuário pode avançar de música em uma playlist. Já o serviço da Apple oferece, hoje, um período de teste de três meses mediante a instalação de um programa no computador do usuário.

O modelo de negócio dos serviços gratuitos de streaming é o chamado Ad Suported, ou serviço financiado por publicidade. Contudo, todos os serviços listados, até mesmo aqueles que não oferecem streaming gratuito, possuem, em sua política de privacidade, cláusulas que lhes permitem acessar e comercializar os dados de navegação dos usuários com empresas de marketing ou comercializar o próprio acesso aos usuários através de cookies ${ }^{12}$ de terceiros.

O serviço Napster dispõe, em sua política de privacidade, ${ }^{13}$ que

Cada usuário [...], por meio deste documento, nos autoriza expressamente a coletar e armazenar suas Informações Pessoais não sensíveis e outras informações comportamentais no banco de dados do Napster, que podem incluir: nome e endereço de e-mail, informações de cobrança, informações sobre software baixado, produtos e conteúdos adquiridos e/ou acessados pelos produtos ou serviços Napster (incluindo, no caso de produtos de música, trilhas transmitidas ou salvas em bibliotecas ou listas de reprodução), informações sobre local (como CEP ou código postal e país), configuração do computador (como sistema operacional, velocidade da conexão e periféricos), a endereço IP da Internet (IP) e URL do site que o enviou à página de registro relevante do Napster, tipos de periféricos (incluindo leitores de mídia portáteis) usados pelos produtos Napster no seu computador (para garantir que você tenha acesso às correções e patches mais recentes para compatibilidade total com esses dispositivos), o identificador exclusivo do seu dispositivo (UDID), local geográfico, informações demográficas fornecidas por você (como idioma, sexo e idade e, se aplicável, preferências de conteúdo e informações de personalização), e se

\footnotetext{
${ }_{12}$ Cookies são pequenos arquivos de texto gravados automaticamente no computador do usuário de internet e que contêm dados trocados entre o navegador e as páginas por ele acessadas. Sua função principal é armazenar dados sobre o acesso, a permanência e o comportamento do usuário em uma página da internet - que sites visitou, por quanto tempo, em que links clicou, com quem interagiu, etc. - que são posteriormente enviados para empresas de processamento de informações. As informações são utilizadas por essas empresas para tentar combinar os anúncios publicitários aos interesses de um usuário. Eles são utilizados em toda a Web, mas, na maioria dos casos, sua presença só é divulgada no interior das políticas de privacidade.

${ }^{13}$ Cf. http://br.napster.com/privacypolicy/?l=pt_BR, consultado a 03.02.2016.
} 
você está conectado ou desconectado do serviço Napster ou se alterou sua senha ou informações de cobrança.

Já sobre o uso de cookies de rastreamento, o serviço Napster afirma coletar dados sobre "o endereço de IP do qual você acessa ao site, o tipo de navegador e os sistemas operacionais usados para acessar o site, data e hora do acesso, páginas que você visitou e endereço do site a partir do qual você chegou ao nosso site" e que esses dados podem ser utilizados para "relatar para terceiros (como anunciantes) estatísticas agregadas sobre nossos usuários em termos de números, padrões de tráfego e informações relacionadas no site" e para "rastrear anonimamente as interações com a publicidade on-line, por exemplo, para monitorar o número de vezes que um anúncio de banner é exibido e o número de vezes em que é clicado". Por fim, o Napster pode, a partir da sua política de privacidade, fornecer o acesso ao usuário diretamente para outras empresas: "O Napster também trabalha com empresas de publicidade on-line que podem usar cookies para rastrear suas preferências de navegação e fornecer anúncios direcionados com base nessas preferências".

Cláusulas semelhantes estão presentes em todos os termos de privacidade dos serviços de streaming ofertados no país, sejam eles gratuitos ou não. É interessante perceber que os modelos de negociação dos dados de navegação dos usuários tornaram-se hegemônicos em relação aos serviços de streaming de música, mesmo naqueles que não oferecem a gratuidade como contrapartida. A comercialização desses registros é mais uma receita gerada a partir da criação de espaços controlados pelos serviços de internet, o que põe em risco, como veremos no próximo capítulo, a privacidade dos usuários da rede. O serviço TIDAL afirma que:

O TIDAL também usa cookies de rastreamento de remarketing de fornecedores terceiros, incluindo o cookie de rastreamento do Google AdWords. Isso significa que vamos continuar a mostrar anúncios para você em toda a Internet, utilizando as redes de anúncios existentes que facilitam este tipo de publicidade. ${ }^{14}$

Já o serviço Apple Music, em sua política de privacidade, aponta que "A Apple e seus parceiros usam cookies e outras tecnologias de serviços de publicidade móvel para controlar o número de exibições de determinado anúncio, mostrar anúncios de acordo com os interesses do usuário e avaliar

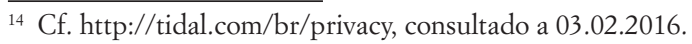


o desempenho das campanhas de publicidade" ${ }^{15} \mathrm{Na}$ mesma política de privacidade, a empresa sugere alguns exemplos de dados captados:

Podemos coletar informações como ocupação, idioma, código postal, código de área, identificador único de dispositivo, URL de referência, localização e fuso horário em que um produto Apple é usado para que possamos entender melhor o comportamento do cliente e melhorar nossos produtos, serviços e propaganda.

Também coletamos informações sobre atividades do cliente em nosso site, nos serviços iCloud e na iTunes Store, e em nossos outros produtos e serviços. Essas informações são agregadas e usadas para nos ajudar a fornecer informações mais úteis para nossos clientes e para entender que partes de nosso site, produtos e serviços são de mais interesse.

Nota-se que esses dados de navegação comercializados, como em todos os espaços analisados aqui, não são gerados apenas na navegação dentro do site específico, mas em toda a navegação do usuário depois que este ter feito o login. Esse direito é apontado na política de privacidade do serviço Spotify. ${ }^{16}$ Segundo o documento, quando versa sobre a instalação de cookies:

Nós usamos esses cookies para fornecer anúncios através do Serviço Spotify. Alguns anúncios podem ser relevantes para você e para seus interesses. Esses cookies podem também ajudar-nos, bem como aos nossos parceiros de negócio, a regular os anúncios que você recebe e a mensurar sua efetividade. [...] terceiros podem usar cookies e outras tecnologias similares para coletar informações sobre suas atividades on-line ao longo do tempo e em diferentes websites.

Outro serviço muito utilizado para o acesso gratuito de música por streaming é a plataforma de vídeos YouTube, da empresa Google. Todas as grandes gravadoras têm um canal próprio no serviço, onde disponibilizam clipes musicais, entrevistas e partes de shows de seus artistas. Desta forma, as empresas conseguem elas mesmas gerar receitas, diretamente com publicidade ou indiretamente como forma de promoção de seus produtos. Além disso, os usuários podem realizar o upload de músicas, álbuns completos, apresentações ao vivo e até de clipes produzidos por eles.

O YouTube é o mais importante serviço de música na internet justamente por não ser projetado especificamente para esse fim. Jimmy Iovine, executivo da Apple Music, afirmou que o YouTube é responsável por 40\% da audição

${ }_{15}$ Cf. http://www.apple.com/br/privacy/privacy-policy/, consultado a 03.02.2016.

${ }^{16}$ Cf. https://www.spotify.com/us/legal/privacy-policy/, consultado a 04.02.2016. 
de música em geral e por apenas $4 \%$ das receitas globais de música. ${ }^{17} \mathrm{~A}$ possibilidade de os usuários colocarem, eles próprios, vídeos na rede, além de ser um terreno fértil para as grandes empresas fonográficas, faz do YouTube, nas palavras de Eric Garland, analista de mídia digital e CEO da agência de pesquisa on-line Big Champagne, o maior acervo de música digital por demanda do mundo. ${ }^{18}$

Embora o YouTube seja uma boa ferramenta de divulgação, promoção e de lucratividade para as empresas fonográficas, o fato de não ter sido projetado para ser um serviço de streaming de música apresenta alguns dilemas para a música digital. Primeiro, o YouTube não tem restrições geográficas a partir da demanda do mercado de música, como nos serviços de streaming. Isso faz com que apresente novidades na música digital sem que haja a possibilidade de compra de discos ou de música digital, estas sim, geograficamente limitadas por estratégias comerciais do mercado musical. Da mesma forma, o YouTube não inclui restrições sobre os suportes em que pode ser executado. A maioria dos serviços do mercado musical restringe o streaming gratuito a computadores pessoais. Se o usuário pretender utilizar o serviço em aparelhos móveis, como smartphones ou tablets, terá que pagar por uma assinatura. Por fim, o YouTube é responsável por um outro movimento relacionado ao acesso à música: através de sua rede, a própria contrafação de música está sendo transferida para o streaming. Com a sucessiva retirada de links dos serviços de armazenamento de arquivos - realizada pela cada vez mais onipotente regra de notificação e retirada (notice and takedown) associada às leis de direito autoral -, o YouTube está constituindo um locus privilegiado para o consumo de música gratuita.

Por esse motivo, o YouTube foi alvo de diversas ações legais promovidas pelas empresas fonográficas. Para combater a contrafação dos direitos autorais em sua rede, inaugurou uma estratégia interessante - chamada de Content $I D^{19}$ - que relaciona a publicação não autorizada e os ganhos com publicidade. O serviço possui um algoritmo que identifica as músicas contidas nos vídeos publicados pelos usuários e as compara com o banco de dados dos titulares previamente cadastrados no Content ID. Caso a música já esteja registrada, o site entra em contato com o detentor dos direitos da música - na maioria das vezes uma grande gravadora que já possui um

\footnotetext{
${ }_{17}$ Cf. http://www.digitalmusicnews.com/2015/10/09/youtube-accounts-for-40-of-all-music-listening-and-4-of-all-music-revenues/, consultado a 09.04.2016.

${ }_{18} \mathrm{Cf}$. http://gizmodo.uol.com.br/o-estado-da-musica-na-internet-youtube-pandora-itunes-e-facebook/, consultado a 09.04.2016.

${ }_{19}$ Cf. https://support.google.com/youtube/answer/2797370?p=cid_what_is\&rd=1, consultado a 08.04.2016.
} 
canal no site - e oferece a opção de esse detentor receber parte do lucro de publicidade daquele vídeo em específico. Além disso, o serviço ainda disponibiliza, no vídeo em questão, links de serviços de venda de música digital - como o iTunes ou a Amazon - para quem pretender adquirir a música legalmente. O diretor do departamento financeiro da gravadora EMI afirmou, durante uma conferência, ${ }^{20}$ que a empresa fonográfica recebia, em 2011, cerca de meio centavo de dólar por visualização. Já segundo o então vice-presidente de conteúdo do YouTube, Tom Pickett, o serviço pagou para a indústria da música, ao longo dos últimos anos, mais de 1 bilhão de dólares americanos. ${ }^{21}$

\section{Streaming de música e o mercado de comercialização de dados dos usuários}

O streaming gratuito de música é, de fato, o que mais aproxima o mercado musical das estratégias do chamado capitalismo informacional (Castells, 1999). A partir dele, a música muda de natureza comercial, deixa de ser negociada diretamente ao consumidor final e é ofertada sob a forma de acesso. As empresas de serviço de música on-line adquirem o direito de disponibilizar músicas através de licenças de uso amparadas nas leis de direito autoral, mas, a partir daí, estas deixam de se aproximar a um bem comercializado para se aproximar de um serviço a favor do marketing. Os "novos modelos de negócio", empreendidos tanto pelas empresas do mercado fonográfico quanto pelas chamadas "empresas de internet", têm, como forma privilegiada de financiamento, as ações de marketing e de peças publicitárias. Para as empresas fonográficas, os modelos baseados na internet como espaço de distribuição e divulgação de música digital financiados por publicidade possibilitam a valorização de ambientes controlados na rede. A música, aqui, é uma isca de uma "economia da atenção" (Goldhaber, 1992, 1997; Lanham, 1994), em que o que é valorizado é o tempo de navegação do usuário em ambientes específicos e sua atenção às peças publicitárias às quais ele é exposto e que são escolhidas exclusivamente para ele.

Jeremy Rifkin, no livro $A$ era do acesso (2001), aponta uma particularidade essencial na transformação do produto em serviço. Segundo ele, os serviços não podem ser confundidos com propriedade. O serviço não é produzido, ele é executado e oferecido, disponibilizado de forma imaterial e intangível e, por essa forma, em uma economia de serviços, o tempo humano é também transformado em commodity. Segundo ele:

${ }^{20}$ Cf. http://torrentfreak.com/images/LW-2011.05.06-Trial-Transcript.pdf, consultado a 09.04.2016.

${ }^{21}$ Cf. http://www.billboard.com/biz/articles/news/digital-and-mobile/5893900/youtube-has-paid-out-1-billion-to-music-industry-in, consultado a 08.04.2016. 
A Era do Acesso é definida, acima de tudo, pela crescente transformação em commodity de toda a experiência humana. Redes comerciais de todos os tipos e formas navegam pela Web em torno da totalidade da vida humana, reduzindo todo o momento de experiência vivida em status. $\mathrm{Na}$ era do capitalismo, caracterizada pela propriedade, a ênfase era vender bens e serviços. Na economia ciberespacial, a transformação de bens e serviços em commodities torna secundária a transformação das relações humanas. Manter a atenção de vendedores e clientes na nova economia de rede em ritmo acelerado, em mudança constante, significa controlar o máximo de tempo possível. (Rifkin, 2001: 79)

$\mathrm{Na}$ economia do acesso às informações nas redes digitais há, portanto, um deslocamento de perspectiva. O que está no centro da atividade econômica é o controle do tempo de navegação e da atenção do usuário, além de seus dados de navegação. O usuário torna-se, ele próprio, através da transformação de sua experiência digital em uma grande quantidade de dados, um produto para uma ecologia de empresas de marketing digital. ${ }^{22}$ Em troca, temos uma oferta legal de música em tamanho, qualidade e facilidade de acesso nunca antes oferecida ao seu consumidor. A transformação da economia da abundância em um modelo de negócio financiado por publicidade não extingue, portanto, a escassez. Apenas a desloca. O que se torna bem escasso, aqui, é o tempo de navegação em que o usuário se dispõe a ser afetado pelas estratégias publicitárias, ou seja, a sua atenção. Esse bem é trocado entre o serviço de internet e as empresas de marketing on-line, e é com essa troca que as empresas fonográficas são pagas. A música, oferecida de forma fácil, abundante e gratuita, tem, como função, atrair o usuário para o ambiente onde a atenção é captada. Quando acessamos a música, estamos nós mesmos sendo acessados.

Essa é a base do que hoje é chamado de "economia da atenção". O pressuposto é que a internet é um espaço que faz com que qualquer informação possa, tendencialmente, tornar-se abundante. Contudo, como aponta Michael Goldhaber (1997), a abundância de informação tem, como consequência, a escassez de atenção. Citando um dos seminais artigos sobre o tema, "Designing Organizations for an Information-Rich World", de Herbert A. Simon (1969), a atenção é aquilo que a informação consome. Um mundo rico em informação gera um mundo pobre em atenção. Aí surge a necessidade de alocá-la de forma eficiente e econômica.

\footnotetext{
${ }^{22}$ O mercado de marketing digital - principalmente aquele voltado ao marketing de comportamento - vem se ampliando e se aperfeiçoando rapidamente. Um infográfico publicado produzido por Scott Brinker para a revista Markerting Land e disponível em http://marketingland.com/martech -companies-double-113921 nos dá uma ideia da complexidade das relações entre diversas empresas do setor (consultado a 08.04.2016).
} 
Para Goldhaber, a internet não gera apenas uma abundância de informação, gera sua inundação (overflowing), e nós estamos nos afogando nela. E, como na lei de Simon, se a informação flui por uma via, a atenção é canalizada como contrapartida. Quanto mais informação, mais a atenção, ela mesma um bem rival e escasso, se dilui. Nesse movimento, a atenção se torna intrinsecamente escassa e, consequentemente, valiosa.

A possibilidade de geração de valor sobre a atenção gera um mercado em que, ao menos em teoria, o consumidor concorda em receber tipos de serviços e mercadorias informacionais em troca do seu tempo de atenção. Quanto mais consumidores-usuários, maior seu estoque de atenção. Contudo, baseado em um mercado concorrencial, quanto mais empresas jogam nesse tipo de economia, mais escassa se torna a atenção do usuário. Nesse sentido, há duas medidas de concorrência: agregar mais informação dentro de um mesmo espaço de valorização da atenção e apresentar informações com maior relevância - ou ao menos com maior atratividade ao consumidor-usuário. É nesse momento que se torna importante a segunda mercadoria criada por essa economia da atenção on-line: a possibilidade de aquisição, através dos termos de uso, dos dados de navegação dos usuários da rede. Quanto mais informações as empresas tiverem sobre os usuários, mais relevantes e atrativos poderão se tornar os ambientes de captura de atenção. Esse é o maior salto qualitativo desse tipo de estratégia de marketing: a atratividade não precisa mais ser massiva, ela pode ser mais ou menos personalizável e individualizada.

Nesse mesmo sentido, a atratividade de um maior número de usuários é uma grande medida concorrencial entre as empresas. A empresa que detiver um maior número de usuários alcança a maior fatia do mercado - como o caso do buscador Google em relação aos dados de busca dos usuários da internet. A qualidade do serviço, sua abrangência, facilidade de utilização, inovação e popularidade - além do valor de utilização - são fundamentais para que o serviço tenha sucesso comercial. No mercado de streaming de música, a preferência do consumidor dá-se em relação à abrangência do catálogo (e os contratos com as grandes empresas de música são fundamentais), o valor da assinatura ou sua gratuidade, a quantidade de plataformas alcançadas pelos serviços (smartphones, computadores pessoais, consolas de video game, etc.), a possibilidade de construir e compartilhar playlists de música, etc. ${ }^{23}$

${ }_{23}$ Cf. http://www.digitalmusicnews.com/2016/01/19/are-we-willing-to-pay-more-for-better -sound-quality/ e http://www.cnet.com/how-to/spotify-rdio-and-more-how-to-get-started-with -subscription-music-services/, consultados a 08.04.2016. 
Seja como for, é importante notar que a aposta do mercado da música nesse modelo de negócio é amplamente vantajosa para o consumidor de música. Os serviços de streaming oferecem mais segurança, abundância e facilidade de aquisição de música do que qualquer serviço ilegal de compartilhamento de arquivos. Isso pode ser observado através das pesquisas sobre a contrafação de música na internet. Segundo um estudo publicado pela empresa de pesquisa em mídia NPD Group, em 2012, a prática de compartilhamento ilegal de música em redes peer-to-peer (P2P) caiu $17 \%$ nos Estados Unidos da América, em comparação com o ano de 2011 e o volume de música presente nas redes P2P diminuiu em 26\% no mesmo período. Já o download ilegal de música por meio de ficheiros virtuais (ciberlockers ou online bosting services) caiu $28 \%$ no país. Segundo a pesquisa, essa queda de percentual tem, como pano de fundo, o surgimento e a popularização de serviços legais e gratuitos de streaming de música (NPD, 2012). Já um estudo realizado pela agência de pesquisa norueguesa Ipsos MMI aponta que, na Noruega, entre o período de 2008 e 2012, o número de downloads ilegais caiu de 1,2 bilhões de arquivos baixados para 210 milhões. Uma queda de 82,5\% (IPSOS, 2013). A análise da queda é a mesma: o aumento de serviços legais de música gratuita ou de baixo custo é a causa principal. Segundo a pesquisa, $47 \%$ dos entrevistados afirmaram ter substituído o download ilegal por alternativas legais de streaming de música e, desses, 50\% afirmaram pagar através de uma conta premium. Já em 2015, o IPTS (Institute for Prospective Technological Studies) da Comissão Europeia publicou um estudo em que também afirma a importância do serviço Spotify para a queda na contrafação digital de música (Aguiar, 2015). Segundo o estudo, os principais serviços de streaming de música foram capazes de reduzir os índices de pirataria de música no continente europeu ao mesmo tempo em que diminuíram, também, o índice de downloads pagos de música.

Ainda no ano 2000, Laymert Garcia dos Santos, em sua palestra intitulada "Consumindo o Futuro" (2003), já havia captado a tendência à hipervalorização do marketing nas empresas de internet em geral e alertou para a ruptura que tais modelos apresentam em sua relação com o consumidor, ao transformá-lo em um tipo especial de mercadoria. Conforme suas palavras:

Apostar na valorização do assinante-consumidor e, administrando o seu consumo, controlar as alavancas da demanda - é exatamente isso que estão fazendo as "dot-com", as empresas da Internet que estão colonizando o ciberespaço e capitalizando o virtual através do conceito de marca. [...] Na nova economia o futuro consumidor é uma mercadoria virtual. Mas uma mercadoria especial: não mais mercadoria que produz mercadorias, como nos tempos do velho Marx, mas sim mercadoria que 
consome mercadorias materiais e imateriais, tanto atuais quanto virtuais. Administrar o consumidor cativo, controlar as alavancas da demanda é, portanto, a quintessência da estratégia de marketing e a ambição máxima de quem deseja direcionar o futuro, antecipando a sua realização. (Santos, 2003: 130-131)

O marketing é uma forma de antecipação do futuro - e, na internet, isso ocorre via prospecção dos dados de navegação dos usuários. Essa economia da gratuidade é financiada por uma atividade que aposta que aquilo que ela financia voltará a tornar-se valor econômico capitalizado. Mas a evolução do marketing é justamente tornar mais real essa antecipação. $\mathrm{O}$ marketing massivo, vinculado às mídias de broadcast - como o rádio ou a televisão - tem muito menos chances de se efetivar do que as estratégias prospectivas personalizadas da internet. Aproveitando-se da característica da comunicação difusiva do broadcast - de poucos para muitos - o marketing vinculado nas chamadas "grandes mídias" está voltado para a venda de poucos produtos para muitas pessoas. Porém, atualmente, segundo os consultores de marketing Don Peppers e Martha Rogers, citados por Rifkin (2001), o objetivo é justamente tentar vender para um único consumidor o maior número de produtos possível.

Para isso, devem elaborar-se estratégias capazes de definir, com a maior exatidão possível, o que o usuário quer, para oferecer-lhe a melhor experiência possível de marketing, e, para isso, as empresas de marketing encontram na internet o espaço de excelência. Estamos cada vez mais transferindo nossas atividades cotidianas para a rede. A internet se tornou espaço de compra, de comunicação, de trabalho e de sociabilidade. Encontramos amigos, fazemos pesquisas de preço, falamos sobre nosso cotidiano, comunicamos com outras pessoas, acessamos produtos culturais e pesquisamos sobre os mais variados assuntos. Nas redes sociais publicamos sobre nossas atividades e interesses, expomos nosso modo de vida, publicamos fotos pessoais, marcamos nossos amigos e lugares de interesse, etc. Estamos, extensiva e exaustivamente, transferindo nossa subjetividade para as redes eletrônicas.

Todavia, tudo que fazemos na internet deixa rastros. Toda nossa navegação é registrada através de cookies e, posteriormente, é enviada para empresas de processamento de informações. Esse é o movimento propiciado pela digitalização dos hábitos a partir da colonização do ciberespaço. Estamos, na internet, interagindo cada vez mais em espaços fechados, estriados, voltados à valorização. Vamos de um espaço fechado para outro, e, como tendência, toda nossa experiência digital se passa em um número menor de ambientes, controlados por um número menor de empresas. Evgeny Morozov (2012), 
um dos mais atentos analistas das recentes transformações da internet, chama o momento atual da rede de "a segunda morte do flaneur". Para ele, as empresas de internet, cada vez mais hegemônicas e concentradas, são como as reformas na arquitetura e no planejamento urbano promovidas em Paris, na segunda metade do século xIx, pelo governo de Napoleão III. Grandes avenidas e praças foram abertas, houve a proliferação da iluminação de rua, e as galerias foram se transformando cada vez mais em lojas de departamento. A possibilidade de passear incógnito, de caminhar sem ser flagrado, de se perder em ruas estreitas, foi substituída pela velocidade dos carros nas grandes avenidas e a organização do espaço como espaço de consumo. $\mathrm{Na}$ internet, as grandes empresas são as grandes avenidas iluminadas, onde não há mais espaço para o passeio, para o anonimato e para se perder. É nas grandes avenidas que se canaliza o fluxo de pessoas e de informações, ambientes hipervalorizados de exposição de produtos e de publicidade.

É a atratividade desses ambientes que faz com que, apesar dos famigerados termos de uso e das políticas de privacidade, os usuários concordem que suas experiências de navegação sejam rastreadas. Basta uma leitura atenta a esses documentos referentes aos serviços de internet desse tipo - que, são, afinal, contratos - para descobrirmos como nossa navegação é vigiada.

Esses dados de rastreamento, captados por empresas de publicidade, são captados em inúmeros lugares na internet. Basicamente, qualquer serviço financiado por publicidade na rede contém alguma forma de rastreamento dos nossos hábitos: quais as informações mais procuradas, os links que acessamos, quanto tempo permanecemos na página, como chegamos àquela página, dentre outros.

\section{Marketing comportamental e a economia da atenção}

Esse é um modelo de negócio em franca expansão na rede, que tem na publicidade sua grande fonte de renda e representa o maior salto em importância das ações de marketing on-line. Através dele adquirimos o acesso aos serviços e aos produtos oferecidos gratuitamente em ambientes controlados por essas empresas; dessa forma trocamos nossos valiosos dados de navegação, que se transformarão em padrões de acesso e de consumo para, enfim, retornarem às nossas vistas como propaganda "personalizada" em grande parte dos locais que visitamos na internet. $\mathrm{O}$ marketing se tornou hegemônico e onipresente nas redes informacionais, capaz de se apresentar de forma muito mais atraente em todo o período de navegação, e fazendo com que o tempo de acesso às redes seja capitalizável.

Somos, portanto, duplamente valiosos como produto digital: pelos nossos hábitos digitalizados e pelo nosso tempo de navegação, em um ciclo que se 
fecha no consumo: "[e]stamos fazendo a transição para o que os economistas chamam de economia da 'experiência' - um mundo em que a própria vida de cada pessoa se torna, de fato, um mercado comercial" (Rifkin, 2001: 6). Nesse meio tempo, a cultura e suas formas de manifestação se tornam atrativos, sendo a sua função manter o usuário em ambientes controlados e que se valorizam através dos seus dados e tempo de navegação.

Tudo se torna uma experiência de marketing. $\mathrm{Na}$ internet, espaço para onde estamos transferindo grande parte de nossas atividades cotidianas, seja no trabalho ou no tempo livre, somos constantemente acessados e afetados por tais estratégias de marketing e controle. As atividades realizadas na rede são pretextos, cujo objetivo é colocar-nos na roda da publicidade on-line. Gilles Deleuze, em "Post-scriptum sobre a sociedade de controle" (1994), no qual captou com excelência as tendências que se desenvolveram nos últimos anos, já alertava sobre essa hegemonia do marketing no capitalismo atual quando apontava que "o marketing é agora o instrumento de controle social, e forma a raça impudente dos nossos senhores", controle esse que é "de curto prazo e de rotação rápida, mas também contínuo e ilimitado" (Deleuze, 1994: 224).

Nesse artigo, escrito em maio de 1990, Gilles Deleuze dissertou sobre o papel chave desempenhado pelas tecnologias informacionais na importante transição das sociedades disciplinares analisadas por Michel Foucault para as Sociedades de Controle. Foucault, em Vigiar e Punir (2004), aponta o surgimento de novas formas de reorganização do sistema judicial e penal baseados em novas relações e práticas de poder. Essas novas relações vão determinar o que ele chama de sociedade disciplinar, que é a própria sociedade moderna. Esse novo tipo de sistema de poder tem o imperativo de se pautar não por uma necessidade social, mas sim por um sistema disciplinar que pretende - e efetivamente consegue - estabelecer relações de vigilância individuais. Parte do pressuposto da periculosidade virtual de todos os indivíduos, que deve ser neutralizada pela vigilância e disciplina constante não só de seus atos, mas de seus próprios corpos. Para esse efeito, a instituição penal ou jurídica deve ser assessorada por uma rede de instituições laterais de poder e de vigilância - tais como a escola, a polícia, as instituições médicas, psicológicas, pedagógicas, criminológicas. Essa forma de poder baseada na vigilância logo se difunde em outras esferas da sociedade e a justificativa da periculosidade basta para um controle econômico, útil e eficiente do corpo, tanto nas instituições escolares como nas médicas ou produtivas, baseado em uma coerção sem folga e um controle ao nível da mecânica, visando sempre a economia e a eficácia dos movimentos. 
Deleuze parte da perspectiva de Foucault ao afirmar que o filósofo, além de identificar com mestria o delineamento das sociedades de disciplina - baseadas na vigilância a partir da organização dos grandes meios de confinamento em espaços fechados -, identificou também a brevidade e a superação desse modelo. Da mesma forma que as sociedades disciplinares sucederam às sociedades da soberania, elas também estavam em vias de serem superadas. Para Deleuze, essa superação começa a ocorrer lentamente a partir da Segunda Guerra Mundial, com a crise dos meios de confinamento e o surgimento de novas liberdades de controle.

Pensar o marketing como controle nos alerta sobre a potência nefasta do rastreamento dos nossos hábitos. Não passamos despercebidos e, a partir de ferramentas digitais voltadas para o lucro, somos constantemente vigiados. O marketing se tornou instrumento político, e o cruzamento das informações coletadas dos nossos hábitos on-line se torna, potencialmente, o maior aparato de vigilância já construído, ${ }^{24}$ causando graves distúrbios em questões relacionadas à privacidade e cidadania, o que, por fim, acaba por interferir no estatuto democrático.

Laymert Garcia dos Santos situa bem o problema quando afirma que, em uma economia movida a partir da digitalização da nossa própria vida cotidiana, "a própria existência do indivíduo é posta em questão":

Aqueles que processam a sua vida descendo a níveis microscópicos não o concebem mais como sujeitos, mas sim como geradores de padrões informacionais que é preciso manipular; aos olhos de quem opera com o valor do tempo de vida, o indivíduo dissolve-se em fluxos de dados. (Santos, 2003: 148)

Esse movimento de hipervalorização da digitalização e do processamento de nossos hábitos na rede acaba por transformar nossos modos de sociabilidade em informação e, como tal, eles se tornam mercadoria. Nessa economia do acesso digital, somos nós que somos acessados, e nossos dados

\footnotetext{
${ }^{24}$ Os documentos vazados por Edward Snowden sobre o programa de espionagem dos serviços de inteligência dos Estados Unidos da América e do Reino Unido nos alertou sobre o caráter político desse tipo de vigilância econômica exercida pelo marketing digital. Quando os dados captados pelas grandes empresas do mercado digital da atenção podem ser acessados por agentes políticos de segurança, forçando sua identificação e apresentando algoritmos eficientes de busca, a vigilância exercida pelo mercado toma uma forma de espionagem política nunca antes conquistada por qualquer tipo de governo. Desta vez, é através da permissividade da vigilância ubíqua implementada por um modelo de negócio que possibilita a formação de um aparato de controle político. A estrutura de captação e processamento de informações já está pronta, atuando de forma eficiente e largamente estabelecida pelas empresas do mercado digital. Basta aos mecanismos de repressão política acessá-las. Esse assunto é mais bem discutido no último capítulo de minha tese de doutorado (Cruz, 2014).
} 
que são a propriedade retida e ofertada como leasing em uma rede que envolve empresas de marketing on-line e empresas de venda de produtos. Entramos aqui como produto e como consumidores de informação. Somos matéria-prima e público-alvo de um complexo mercado de marketing. De um lado, consumimos serviços e mercadoria-informação em eficientes ambientes digitais. Por outro, tais ambientes recolhem e processam valiosos dados que os retroalimentam, tornando-os mais atrativo ao consumidor e servindo de matéria-prima para uma complexa rede de mercado do marketing comportamental.

Assim, como previu Gilles Deleuze (1994), deixamos de ser indivíduos para nos tornarmos divíduos, divisíveis e cindidos em nosso corpo biológico e nosso corpo de dados, numérico, mantidos em banco de dados para o processamento de informações, em um movimento que começa com o surgimento das pesquisas em marketing e que conquistou seu corolário com o chamado Big Data. Na sociedade do controle, somos constantemente modulados a cada acesso, em um movimento contínuo e ilimitado, onde nunca se termina o que quer que seja. É a partir do processamento constante de nosso corpo de dados e de seu movimento nas redes digitais que somos descobertos e analisados, mas apenas naquilo que interessa ao processo de capitalização e de controle: o que pode se tornar padrão e ser revertido em propriedade. Não temos identidade em nosso corpo de dados: somos um número identificador (IP), uma conta, uma cifra ou um número estatístico, mas ele pode conter mais informações sobre nós do que aquilo que nós mesmos conseguimos registrar.

A transformação do consumidor em produto é a maior façanha desse novo modelo de negócio digital, e isso ocorre via digitalização dos nossos gostos e via mercantilização de nossa atenção e de nosso tempo de navegação.

O que está em jogo aqui é a capacidade de estimular, racionalizar e controlar a atenção do usuário, e isso é conquistado através das tecnologias de digitalização e processamento dos nossos hábitos on-line. As possibilidades de processamento e categorização da nossa experiência de navegação possibilitam uma apuração da nossa percepção em ambientes digitais e a fazem funcionar dentro de um regime econômico específico. Um certo uso das tecnologias digitais de rastreamento é capaz de colocar nossa atenção dentro de um tipo de arquitetura de controle voltada, em um primeiro momento, para a valorização.

A busca pela possibilidade de racionalização da percepção em geral e sua relação com técnicas de gerenciamento da atenção não é novidade. Essa relação atua historicamente em nossos corpos e ajudou a formar, na modernidade, nossa forma de perceber o mundo. Essa é a tese de Jonathan Crary, 
em seu livro Suspensões da percepção: atenção, espetáculo e cultura moderna (2013), uma genealogia da atenção entre os séculos XIx e xx dentro daquilo que ele chama de modernização da subjetividade.

Em sua obra, Crary (2013) insere a percepção e a atenção dentro do processo de captura, disciplinarização e controle do corpo, que atua sobre o campo social através de uma série de técnicas externas. A ideia geral do autor é demonstrar que os modos pelos quais ouvimos, olhamos ou nos concentramos em algo possui um arraigado caráter histórico. Nossa atenção não é uma condição natural, mas "o produto de uma densa e poderosa recomposição da subjetividade humana no Ocidente ao longo dos últimos 150 anos" (ibidem: 25).

No centro desse processo analisado por Crary estão as relações entre o observador, as inovações nas tecnologias de percepção e a prática artística. Como bem aponta Stella Senra, autora do prefácio da edição brasileira da obra Suspensões da percepção, a análise de Crary desloca a linha divisória entre arte e técnica ao afirmar que a transformação de status da percepção "passa tanto por máquinas de visão quanto por rupturas no próprio exercício da pintura” (Senra, 2013: 10). O próprio autor afirma que as novas qualidades dos estudos sobre a percepção só tiveram lugar no limiar histórico da segunda metade do século xix, "em que começou a evaporar qualquer diferença qualitativa importante entre a vida e a técnica" (Crary, 2013: 35).

Portanto, para Crary, as tecnologias do espetáculo, exposição, projeção, atração e registro alteram definitivamente as experiências sensoriais dos sujeitos modernos. Dado o modo de produção e difusão dessas tecnologias no então nascente capitalismo industrial, tais transformações sensoriais se tornam inseparáveis dos processos econômicos, sociais e políticos. Mais do que isso, o processo de disciplinarização da atenção tornou-se um problema que se incluía na organização do trabalho e da produção do capitalismo industrial.

A possibilidade de reformatar processos sonoros, visuais, informacionais e energéticos em mercadorias quantificáveis e passíveis de distribuição fez com que a administração da atenção abrisse caminhos cada vez mais complexos dentro do campo social e que a nossa atenção passasse a depender, cada vez mais, do ajustamento à contínua reconfiguração técnica, política e econômica das formas de consumo do mundo sensorial. Portanto, dentro de uma série de descontinuidades históricas no mundo do trabalho, do consumo e do modo de produção do capitalismo contemporâneo, resta-nos perguntar - bem como fez Stella Senra e Emerson Freire -, em que tipo de compasso e de descompasso se encontra nossa atenção nos dias 
de hoje em relação àquela analisada por Crary? Se a atenção e a experiência perceptiva puderam ser administradas dentro do escopo da ortopedia social na sociedade disciplinar e colocadas assim à mercê de um sistema econômico e produtivo assente no industrialismo e na produção direta de mercadorias, como elas se comportam hoje, com a falência dos aparatos disciplinares e com a emergência da sociedade do controle?

Freire insere o deslocamento da administração da atenção justamente dentro das transformações sociais articuladas por Michel Foucault (2004) e Gilles Deleuze (1994) - a mudança nos dispositivos e na administração de poder, de uma sociedade disciplinar para uma sociedade do controle. Para ele, se a atenção pode ser identificada, mensurada e administrada por uma série de estímulos técnicos, a transformação das máquinas energéticas da sociedade disciplinar para as máquinas cibernéticas da sociedade do controle eleva as possibilidades de controle da atenção a níveis qualitativamente diferentes. Dentro desse novo paradigma, o modelo de observador se transforma, bem como a própria experiência sensorial. Há aí um problema de natureza e de modus operandi na possibilidade de captura. A atenção é capturada e mensurada não só como estímulo, mas como relação entre o observador e a máquina. Segundo Freire,

Há outra velocidade envolvida que desloca o foco da atenção para a capacidade de leitura de padrões fragmentados, uma torrente de dados e informações que surgem no monitor deve ser 'lida' rapidamente e/ou ainda deve disparar ações dos que jogam em uma lan-house, por exemplo. Por isso, às vezes, tem-se a impressão de que o ponto da atenção até deslocou-se para a máquina, quem está atenta é a máquina através do software, que tem a capacidade de conduzir os operadores em rede, uma espécie de atenção compartilhada com a máquina. (2012: 185-186)

As recentes tecnologias perceptivas das redes digitais inauguraram a possibilidade de acesso e de modulação da observação através da análise dos rastros digitais captados na relação interativa dos usuários com a máquina e com os estímulos que ela produz. Assim, fez-se possível a hegemonização da captura, da mensuração da observação e da atenção e sua consolidação dentro dos sistemas econômicos, políticos e produtivos.

É nesse sentido que Stella Senra (2013) sugere que a possibilidade de gerência da atenção nas redes informacionais e a formação de uma eficiente economia da atenção acontecem a partir de uma transformação essencial na própria operação de captura da experiência sensorial. O que está no centro do controle da atenção agora não é mais a resposta aos estímulos, mas a possibilidade cada vez maior de digitalização e de processamento 
dessa resposta, que pôde, assim como tudo aquilo cujas qualidades puderam ser processadas como dados, tornar-se cada vez mais permeável às operações de controle.

É esse o sentido da economia da atenção realizada pelos novos modelos de negócio das empresas de internet. A possibilidade de modulação da atenção, em um desdobramento não linear da administração da percepção, fez com que o tempo de navegação dos usuários das redes digitais pudesse adquirir valor de troca. Diferente das estratégias de marketing que financiam há tempos os meios de entretenimento de massa, cujo período de atenção é calculado abstratamente e baseado na média de audiência que um conteúdo pode atingir e cuja prospecção do público-alvo era baseado no perfil também abstrato dos interessados por esse conteúdo, a captura e o processamento dos dados de navegação fazem com que o próprio usuário se torne uma mercadoria escassa e valorizada pelo marketing on-line.

\section{Considerações finais}

Vimos, no decorrer deste artigo, que as novas estratégias de inserção do mercado fonográfico na rede - em especial os novos serviços de streaming por demanda, em grande crescimento na rede - apresentam uma nova forma de distribuição comercial da música digital. Nele, o mercado de música pôde se valorizar através de um modelo de negócio que concorre com a gratuidade e abundância da contrafação digital da música ${ }^{25}$ e se pautar na característica própria da digitalização: a produção e distribuição rápida, barata e eficiente de cópias. Nesse caso, ao dispor a música de forma abundante e gratuita, a escassez, essencial para o estabelecimento de um mercado e para a formação do valor, teve que ser deslocada da música para os usuários. Vimos que, nesse novo mercado, ao acessar os produtos culturais e serviços digitalizados, ofertados, em grande medida, de forma gratuita em ambientes fechados, os usuários desses serviços são também transformados em produto através da digitalização do nosso comportamento na rede e do nosso tempo de navegação.

\footnotetext{
${ }^{25}$ É interessante perceber que isso começa a ocorrer não só no campo da música digital, mas em grande parte no da produção cultural digitalizada. Um exemplo disso é a constante queda de tráfego das redes de compartilhamento peer-2-peer - em especial as redes BitTorrent, popularizadas principalmente pelo grupo The Pirate Bay - e o aumento do tráfego de serviços legais de streaming, como o Netflix. Em um estudo realizado pela empresa de serviços de banda-larga estadunidense Sandvine, o fluxo de dados relacionados a downloads em redes torrent caiu consideravelmente na América do Norte. Em 2008, os dados das redes BitTorrent correspondiam a 31\% de todos os dados trafegados na internet na América do Norte. Em 2014, esse número foi de 4,85\%. Por outro lado, os dados do serviço de streaming de vídeo Netflix ocuparam 33,81\% de todo o tráfego de dados da América do Norte em 2014.
} 
Contudo, esse novo negócio só se apresenta de forma funcional através de dois movimentos interdependentes: a valorização dos ambientes onde a música é acessada e a efetividade das estratégias de repressão aos ambientes não autorizados a participar desse mercado. É só através da criação de espaços fechados na rede - o site ou aplicativo que oferta uma grande quantidade de música, acessada de forma fácil, gratuitamente ou a preços bem reduzidos, onde os usuários devem ficar permanentemente conectados para acessar a música e ser acessados pelos dispositivos de publicidade - que os novos atores desse mercado podem controlar o fluxo de dados trocados nas operações de acesso. De forma conjunta, é só através das estratégias de repressão, como os dispositivos de "notificação e retirada", que esses ambientes fechados podem ser apontados como ambientes legais e seguros de acesso à música. Nesse caso, a abundância, a gratuidade e a facilidade de acesso à música digital se torna uma forma eficiente de atratividade, usada como um serviço do marketing digital.

\section{Referências bibliográficas}

Aguiar, Luiz; Waldfogel, Joel (2015), Streaming Reaches Flood Stage: Does Spotify Stimulate or Depress Music Sales? European Commission, Joint Research Centre Sevilha. Consultado a 25.01.2016, em https://ec.europa.eu/jrc/sites/default/files/JRC96951.pdf. Castells, Manuel (1999), A sociedade em rede. São Paulo: Paz e Terra.

Crary, Jonathan (2013), Suspensões da percepção: atenção, espetáculo e cultura moderna. São Paulo: Cosac Naify.

Cruz, Leonardo Ribeiro da (2014), Internet e arquiteturas de controle: as estratégias de repressão e inserção do mercado fonográfico digital. Tese de Doutorado apresentada à Universidade Estadual de Campinas, Campinas, Brasil. Consultado a 26.06.2015, em http://www. bibliotecadigital.unicamp.br/document/?code=000941869.

Deleuze, Gilles (1994), "Post-Scriptum sobre as sociedades de controle", in Gilles Deleuze, Conversações. São Paulo: Editora 34, 221-224.

Doctorow, Cory (2012), "O Pecado Original", Caderno Link. 22 de julho. Consultado a 26.06.2015, em http://blogs.estadao.com.br/link/o-pecado-original/.

Foucault, Michel (2004), Vigiar e punir. Petrópolis: Vozes.

Freire, Emerson (2012), Da sensação ausente à sensação como potência: tema e variações sobre a relação arte-tecnologia. Tese de Doutorado apresentado à Universidade Estadual de Campinas, Campinas, Brasil.

Goldhaber, Michael H. (1992), "The Attention Society", Release 1.0, (26 March), n. ${ }^{\circ} 3$, E. Dyson (org.), New York: EDventure Holdings, 1-20.

Goldhaber, Michael H. (1997), "The Attention Economy and the Net”, First Monday, 2(4), 7 de abril de 1997. Consultado a 26.06.2015, em http://firstmonday.org/article/view/519/440. 
Greenburg, Zack O’Milley (2015), “Como as gravadoras estão se apoderando da multibilionária revolução digital”, Forbes Brasil, 18 de dezembro. Consultado a 12.01.2016, em http://www.forbes.com.br/negocios/2015/12/como-as-gravadoras-estao-se-apoderando -da-multibilionaria-revolucao-digital/.

IFPI - International Federation of the Phonographic Industry (2008), Digital Music Report 2008. IFPI.org. Consultado a 08.04.2016, em http://www.ifpi.org/content/ library/DMR2008.pdf.

IFPI - International Federation of the Phonographic Industry (2015), Digital Music Report 2015. IFPI.org. Consultado a 26.06.2015, em http://www.ifpi.org/downloads/ Digital-Music-Report-2015.pdf.

IPSOS - Ipsos MediaCT (2013), Kopiering av opphavsrettslig beskyttet innhold i 2012. Utarbeidet for Norwaco. Consultado a 17.01.2016, em http://www.aftenposten.no/ incoming/article7254471.ece/BINARY/Rapport+om+kopierin g.pdf.

Lanham, Richard (1994), "The Economics of Attention", Atas do 124. ${ }^{\circ}$ Encontro anual da Association of Research Librarians, 18-20 de maio, Austin, Texas, Estados Unidos da América. Consultado a 20.01.2016, em http://old.arl.org/resources/pubs/ mmproceedings/124mmlanham.

Morozov, Evgeny (2012), “A segunda morte do flâneur”, Caderno Link, 19 de fevereiro.

Nielsen (2014), U.S. Music Industry Year-End Review: 2013. Nielsen. Consultado a 26.06.2015, em http://www.nielsen.com/us/en/insights/reports/2014/u-s-music-industry-year-end-review-2013.html.

Nielsen (2015), 2014 Nielsen Music Report. Nielsen. Consultado a 26.06.2015, em http:// www.nielsen.com/us/en/press-room/2015/2014-nielsen-music-report.html.

NPD - The NPD Group (2012), Music File Sharing Declined Significantly in 2012. NPD Group. Consultado a 17.12.2015, em https://www.npd.com/wps/portal/npd/us/news/ press-releases/the-npd-group-music-file-sharing-declined-significantly-in-2012/.

RIAA - Recording Industry Association of America (2012), 2011 Year End Shipment Data. RIAA. Consultado a 17.01.2016, em http://www.marketingfx.com/downloads/1460556363.04470000_aebf73f2dc/2011\%20RIAA\%20Shipments.pdf.

Rifkin, Jeremy (2001), A era do acesso. São Paulo: Makron Books.

Santos, Laymert Garcia dos (2003), Politizar as novas tecnologias. São Paulo: Ed. 34.

Senra, Stella (2013), "Crary e as transformações do observador", in Jonathan Crary, Suspensões da percepção: atenção, espetáculo e cultura moderna. São Paulo: Cosac Naify, 9-19.

Simon, Herbert (1969), Designing Organizations for an Information-Rich World. Baltmore: John Hopkins University Press.

Virilio, Paul (1999), A bomba informática. São Paulo: Estação Liberdade. 
Artigo recebido a 29.06.2015

Aprovado para publicação a 24.03.2016

\section{Leonardo Ribeiro da Cruz}

Doutor em Sociologia pelo Instituto de Filosofia e Ciências Humanas da Universidade Estadual de Campinas (IFCH/UNICAMP)

Avenida Jeanne Rosande Guisard, 495, Taubaté-SP, CEP 12050-560, Brasil

Contacto: leocruz.0@gmail.com

\section{The New Digital Music Business Models and the Attention Economy}

This article aims to analyse the music industry's strategies for economic integration within the digital environment, in particular the new, free, on-demand streaming services. It discusses the changing nature of commercial music - which is no longer marketed directly but developed as a behavioural marketing service - and how the prerequisites for this new model are, on the one hand, a mass of free music, but also the use of user navigation data and attention time. It concludes by examining how this new service in the recorded music market fosters the hegemony of the online attention economy and ubiquitous surveillance, and also helps expand closed spaces on the network geared to market values at the expense of free and open spaces.

Keywords: attention economy; audio streaming; digital music; marketing strategies; phonographic industry.

\section{Les nouveaux modèles d'affaire de la musique digitale et l'économie de l'attention}

Le présent article se penche sur les stratégies d'insertion du marché phonographique dans l'environnement digital, en particulier les nouveaux services gratuits de streaming à la demande. Nous faisons une approche du changement de la nature commerciale de la musique - qui n'est plus commercialisée directement pour être valorisée comme un service du marketing comportemental - et de la façon dont ce nouveau modèle $a$, comme présupposé, d'une part les caractéristiques de l'abondance et de gratuité de la musique et, d'autre part, la valorisation des données de navigation et du temps d'attention des usagers. Enfin, le texte débat de la façon dont ce nouveau service favorise l'hégémonie de l'économie de l'attention online et la surveillance omniprésente et aide à l'expansion d'environnements digitaux fermés, produits uniquement par le marché au détriment d'espaces libres et ouverts. Mots-clés: économie de l'attention; industrie phonographique; musique digitale; stratégies de marketing; streaming audio. 